Case Report

\title{
Surgical Resection for a Second Primary Lung Cancer Originating Close to the Initial Surgical Margin for Lung Squamous Cell Carcinoma
}

\author{
Seijiro Sato, Terumoto Koike, Takehisa Hashimoto, and Masanori Tsuchida \\ Division of Thoracic and Cardiovascular Surgery, Niigata University Graduate School of Medical and Dental Sciences, \\ 1-757 Asahimachi-dori, Chuo-ku, Niigata-shi, Niigata 951-8510, Japan
}

Correspondence should be addressed to Seijiro Sato; okura1127@gmail.com

Received 9 December 2014; Revised 17 February 2015; Accepted 26 February 2015

Academic Editor: Steve de Castro

Copyright (C) 2015 Seijiro Sato et al. This is an open access article distributed under the Creative Commons Attribution License, which permits unrestricted use, distribution, and reproduction in any medium, provided the original work is properly cited.

\begin{abstract}
Few reports have described surgical resection for second primary lung cancers originating close to the initial surgical margin for lung cancer. A 64-year-old man had undergone left segmentectomy with lymph node dissection for small peripheral squamous cell lung cancer using video-assisted thoracic surgery, with pathology confirming a small tumor $12 \mathrm{~mm}$ in diameter identified about $3 \mathrm{~cm}$ from the surgical margin. Eighteen months after initial surgery, computed tomography revealed a 30 mm pulmonary nodule close to the initial surgical margin in the residual left upper lobe and the serum level of carcinoembryonic antigen was found to be increased. Local recurrence on the staple-line of the surgical margin was suspected, and completion left upper lobectomy was performed. Histological examination identified not only a squamous cell carcinoma component but also a small cell carcinoma component. The immunohistochemical staining pattern of the second tumor differed from that of the initial resected lung squamous cell carcinoma. The final pathological diagnosis was a second primary tumor with mixed small cell carcinoma and squamous cell carcinoma histology.
\end{abstract}

\section{Introduction}

In recent times, small peripheral malignant lung tumor has increasingly been treated by limited resection using videoassisted thoracic surgery (VATS) to minimize the volume of lung resected and the size of the thoracotomy incision [1]. Staplers have routinely been used and various complications of the surgical margins have been reported [2-4] with this increasing use. A new lesion originating close to the initial surgical margin during postoperative follow-up is one such complication. Principal differential diagnoses for such lesions include local recurrence of the initial lung malignancy, nontuberculous mycobacterial infection or fungal infection caused by nonanatomical stapling, and foreign-body granuloma. However, in addition to these diseases, the possibility of a second primary lung cancer should be considered. To the best of our knowledge, only one previous report [5] has described a second primary lung cancer originating close to the initial surgical margin. We report herein a case of a second primary lung cancer originating close to the initial surgical margin for a previous lung squamous cell carcinoma and treated by surgical segmentectomy.

\section{Case Presentation}

A 64-year-old man underwent segmentectomy with lymph node dissection for lung cancer of left segments $1+2$ in March 2012. Pathologically, the tumor was diagnosed as a moderately differentiated squamous cell carcinoma, measuring $12 \times 8 \mathrm{~mm}$ (pTlaN0M0). Immunohistochemical staining showed positive expression of CK5/6 and p63 and negative expression of thyroid transcription factor 1 (TTF1), CD56, chromogranin A (CGA), and synaptophysin. The tumor was about $3 \mathrm{~cm}$ from the surgical margin and no residual cancer cells were identified (Figure 1). In October 2013, serum levels of carcinoembryonic antigen (CEA) were found to be elevated. Computed tomography (CT) revealed a $30 \mathrm{~mm}$ pulmonary nodule close to the initial surgical margin 


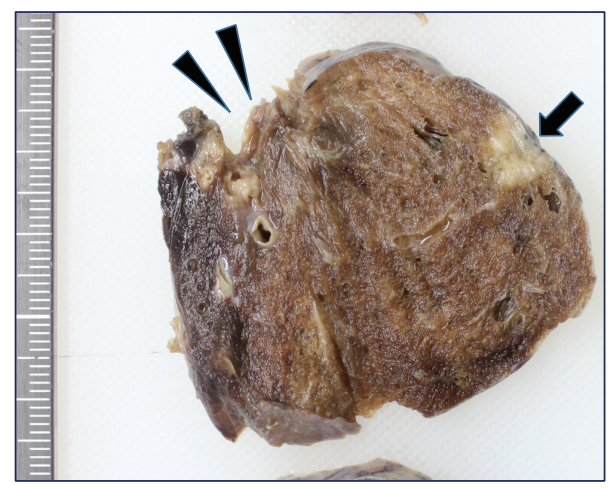

Figure 1: The tumor (arrow) measuring $13 \mathrm{~mm}$ is about $3 \mathrm{~cm}$ away from the surgical margin (arrowhead).

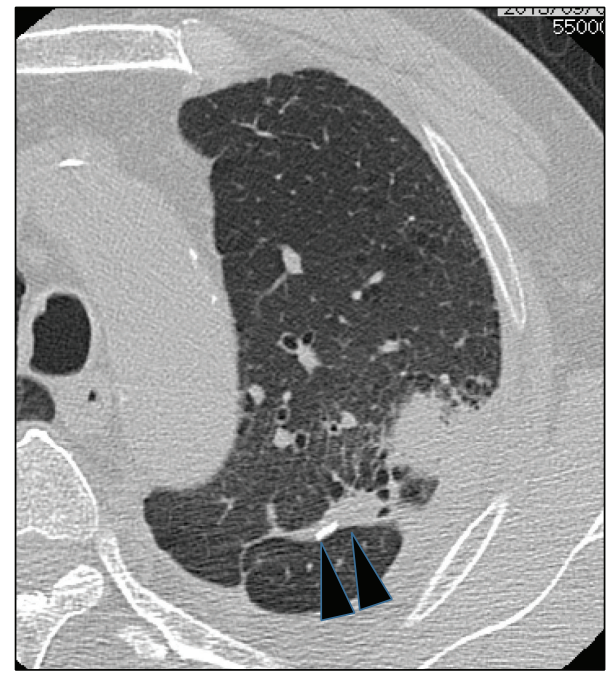

FIGURE 2: Chest CT reveals a $30 \mathrm{~mm}$ pulmonary nodule close to the initial surgical margin (arrowhead).

(Figure 2). Positron emission tomography (PET) with ${ }^{18} \mathrm{~F}$ fluorodeoxyglucose (FDG) showed uptake by the tumor, but no region of uptake other than the equivocal uptake area. In November 2013, the patient was admitted on suspicion of local recurrence along the staple-line of the surgical margin. He had a 44-year history of smoking 1 pack/day until 2 years earlier. Physical examination yielded normal results. Laboratory data showed that the serum level of CEA was $12.1 \mathrm{ng} / \mathrm{mL}$ (normal, $<4.3 \mathrm{ng} / \mathrm{mL}$ ), and pro-gastrin-releasing peptide (ProGRP) level was $134 \mathrm{pg} / \mathrm{mL}$ (normal, <81 pg/mL). Pulmonary function testing showed normal result. Reoperation was performed, with intraoperative rapid diagnosis suggesting squamous cell carcinoma, and completion left upper lobectomy was performed.

Macroscopically, the tumor was a solid, whitish mass measuring $32 \times 25 \mathrm{~mm}$ and showing partial necrosis. Histological examination identified a main small cell carcinoma component with a high nuclear-cytoplasmic ratio, unclear nucleoli, and fine chromatin (Figure 3(a)) and a smaller squamous cell carcinoma component (Figure 3(b)). Immunohistochemically, tumor cells of the small cell carcinoma component showed positive staining for thyroid transcription factor 1 (TTF-1), chromogranin A (CGA), synaptophysin, and CD56 (Figure 3(c)) but negative staining for p63 and CK5/6 (Figure 3(d)). By contrast, cells of squamous cell carcinoma component were positive for p63 and CK5/6 (Figure 3(d)) but negative for TTF-1, CGA, synaptophysin, and CD56 (Figure 3(c)). The staining pattern of the second tumor differed from that of the squamous cell carcinoma resected from the lung previously. For these reasons, pathological diagnosis was a second primary combining small cell lung carcinoma and squamous cell carcinoma and intrapulmonary lymph node metastasis (pT2aN1M0). The postoperative course was uneventful, and the patient received chemotherapy for small cell lung cancer.

\section{Discussion}

Reports of lung tumors close to the initial surgical margin of a resected lung cancer resection are gradually increasing as reduction surgeries and staplers for dissection of the intersegmental plane see greater use. One differential diagnosis is surgical-margin recurrence after lung cancer resection. Another is an infectious mass occurring after ventilatory impairment and blood flow obstruction in the lung tissue from stapling result in the development of an infection from pathogens that were present preoperatively [3]. A third possibility is foreign-body granuloma, a noninfectious mass resulting from a foreign-body (antigen) response activating T-cells and macrophages that cause epithelioid cells and giant cells to emerge [5].

In making a differential diagnosis from imaging, CT often reveals a noncancerous lesion with a linear margin, calcification, diffuse shadows, and no involvement of blood vessels and bronchial tubes $[6,7]$. Recent reports have indicated that fluorodeoxyglucose- (FDG-) PET is not particularly informative, with a diagnostic sensitivity for malignancy of $63 \%$, specificity of $56 \%$, and a proper diagnosis rate of $60 \%$ for nodes $\leq 30 \mathrm{~mm}$ and a threshold maximum standardized uptake value (SUVmax) of 2.5 [8].

Including the present report, 13 cases of lung masses close to the initial surgical margin have been reported in Japan (Table 1) [2-5, 9-16]. However, many represented nontuberculous mycobacteria or foreign-body granuloma. Diagnosis was obtained in only one [5] of the five cases in which preoperative diagnosis was attempted, indicating that preoperative diagnosis is very difficult. Only four patients underwent PET-CT preoperatively, and the SUVmax for the infectious mass [3] was high, at 4.59, suggesting difficulty in using this approach to identify malignancy. Only two of the 13 patients were diagnosed with a second primary lung cancer, and multiple primary lung cancers are extremely rare.

At present, the adequacy of segmentectomy for lung cancers $\leq 2 \mathrm{~cm}$ with radiologically pure solid lesion remains controversial. The results of ongoing prospective randomized trials of lobar versus sublobar resection in patients with small peripheral non-small-cell lung cancers, such as JCOG 


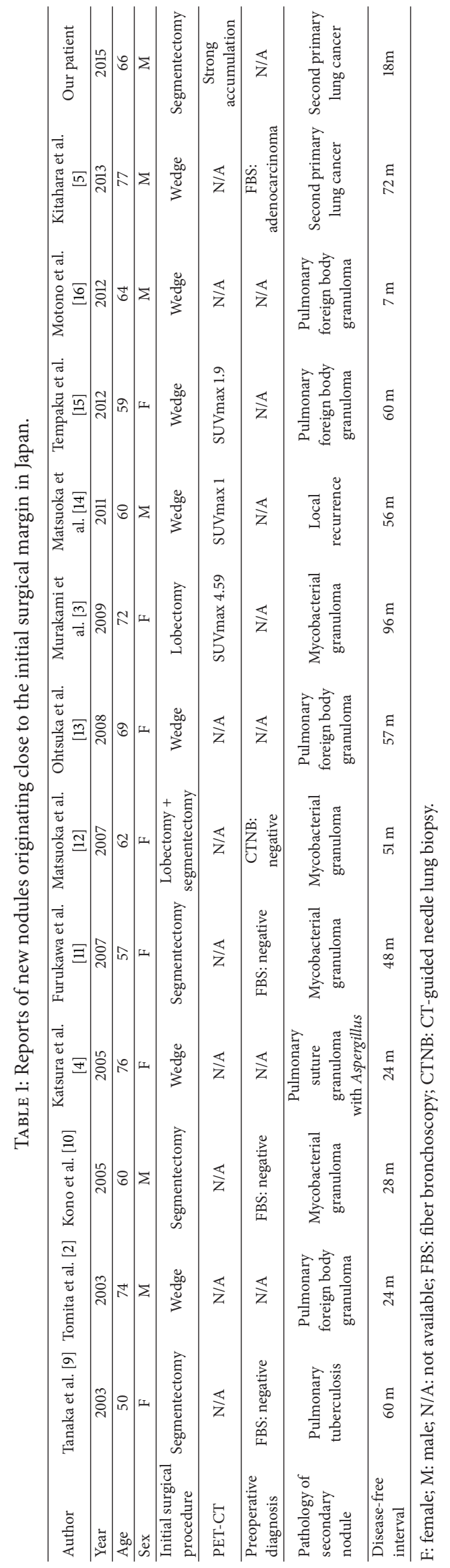




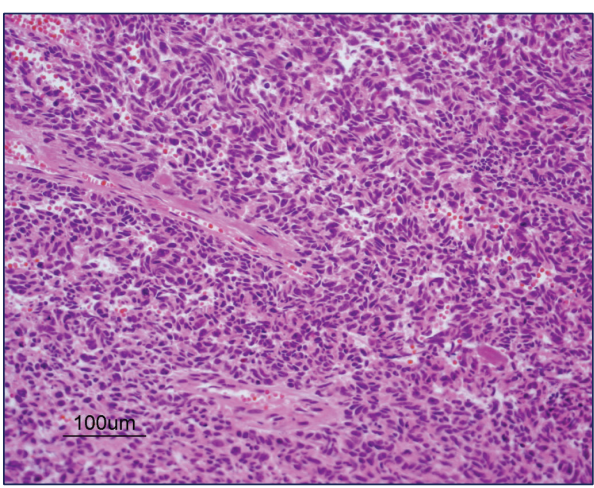

(a)

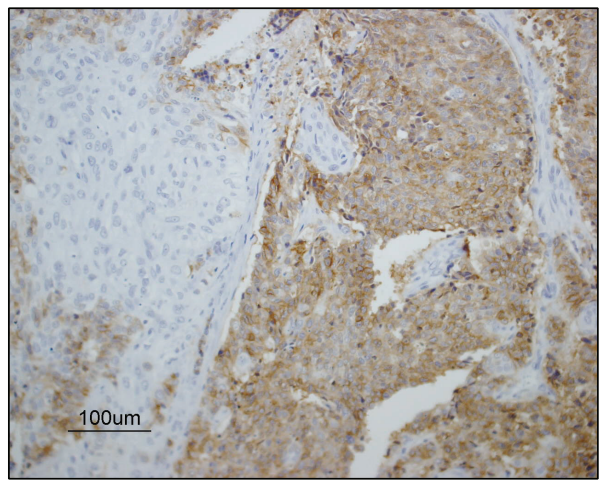

(c)

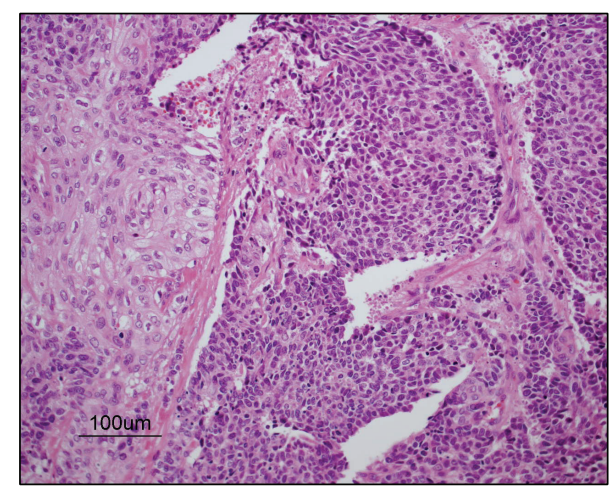

(b)

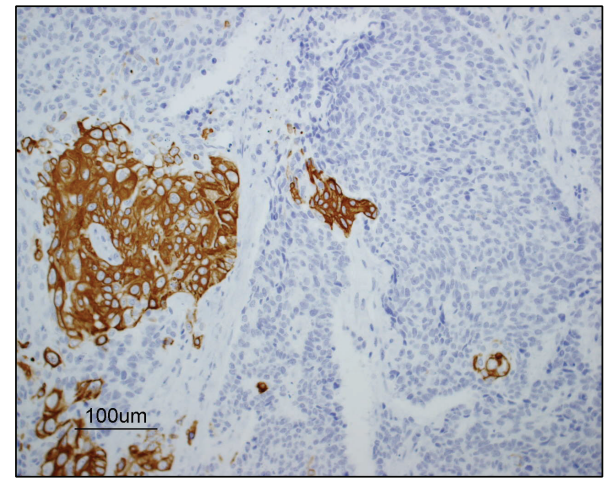

(d)

FIGURE 3: Histopathological examination shows that the tumor comprises a main small cell carcinoma component (a) and a smaller squamous cell carcinoma component (b). Immunohistochemically, tumor cells of the small cell carcinoma component show positive staining for CD56 (c) but negative staining for CK5/6 (d). By contrast, cells of squamous cell carcinoma component were positive for CK5/6 (d) but negative for CD56 (c).

0802/WJOG 4607L [17], are eagerly awaited. We performed segmentectomy for the lung cancer $\leq 2 \mathrm{~cm}$ with pure solid component at initial surgery, because no involvement of hilar lymph nodes was evident intraoperatively.

In the present case, there were several reasons why we diagnosed the tumor as a second primary lung cancer rather than local recurrence along the staple-line of the surgical margin. First, from the perspective of the histological findings, including immunohistochemical staining, the lung cancer specimen from the initial surgery differed from the second primary specimen. The pathological diagnosis was squamous cell lung cancer in the initial surgery, compared to combined small cell lung cancer and squamous cell lung cancer in the second surgery. Second, a few reports $[18,19]$ have described cases in which EGFR-mutant non-small-cell lung carcinoma has acquired resistance to EGFR-TKI therapy through transformation to small cell lung cancer. However, the patient in this case had not received any postoperative treatment for cancer, including molecular targeted therapy, and local recurrence of the initial squamous cell carcinoma with transformation to small cell lung cancer was deemed highly unlikely. Third, the second primary tumor was about $3 \mathrm{~cm}$ from the initial resection stump.

\section{Conclusion}

Cases of new nodule originating close to the initial surgical margin seem to have increased in frequency, possibly because selected limited resection and the use of staplers for dissection of the intersegmental plane have increased. In addition to local recurrence, infectious nodules, and foreign-body granuloma, the possibility of a second primary lung cancer should be considered in such cases.

\section{Conflict of Interests}

The authors declare that there is no conflict of interests regarding the publication of this paper.

\section{References}

[1] J. Amano, H. Kuwano, and H. Yokomise, "Thoracic and cardiovascular surgery in Japan during 2011: annual report by the Japanese Association for Thoracic Surgery," General Thoracic and Cardiovascular Surgery, vol. 61, no. 10, pp. 578-607, 2013.

[2] M. Tomita, Y. Matsuzaki, M. Edagawa, T. Shimizu, M. Hara, and T. Onitsuka, "Pulmonary granuloma possibly caused by staples 
after video-assisted thoracoscopic surgery," Annals of Thoracic and Cardiovascular Surgery, vol. 9, no. 2, pp. 123-125, 2003.

[3] S. Murakami, H. Saito, M. Tsuboi, H. Nakayama, Y. Kameda, and K. Yamada, "Mycobacterial granuloma on the staple-line eight years after middle lobectomy for adenocarcinoma of the lung," Japanese Journal of Lung Cancer, vol. 49, no. 7, pp. 10381042, 2009.

[4] H. Katsura, K. Iuchi, and A. Matsumura, "Pulmonary suture granuloma with Aspergillus after partial resection for lung cancer; report of a case," Kyobu Geka, vol. 58, no. 2, pp. 169-171, 2005.

[5] A. Kitahara, T. Aoki, and M. Yazawa, "Surgical treatment for 2nd primary lung cancer originated close to the initial surgical margin for bronchioloalveolar carcinoma (BAC); report of a case," Kyobu Geka, vol. 66, no. 2, pp. 165-168, 2013.

[6] N. Takanashi, Y. Nobe, H. Asoh, T. Yano, and Y. Ichinose, “The diagnostic accuracy of a solitary pulmonary nodule, using thinsection high resolution CT: a solitary pulmonary nodule by HRCT,' Lung Cancer, vol. 13, no. 2, pp. 105-112, 1995.

[7] H. Saito, "Diagnosing characteristics of pulmonary nodules using thin-section CT images," Japanese Journal of Lung Cancer, vol. 48, no. 4, pp. 302-311, 2008 (English).

[8] Y. Ohno, M. Nishio, H. Koyama et al., "Comparison of quantitatively analyzed dynamic area-detector CT using various mathematic methods with FDG PET/CT in management of solitary pulmonary nodules," American Journal of Roentgenology, vol. 200, no. 6, pp. W593-W602, 2013.

[9] H. Tanaka, K. Iuchi, A. Matsumura et al., "Pulmonary tuberculosis post staple-segmentectomy for lung cancer," The Journal of the Japanese Association for Chest Surgery, vol. 17, no. 7, pp. 794-797, 2003.

[10] Y. Kono, S. Endo, S. Otani et al., "Non-tuberculous mycobacterial infection along the staple-suture line after segmentectomy for small peripheral lung cancer; report of a case," Kyobu Geka, vol. 58, no. 2, pp. 165-168, 2005.

[11] M. Furukawa, H. Ikeda, M. Takeo, and M. Yamamoto, "Pulmonary granuloma associated with nontuberculous mycobacteriosis occurring in the staple used for operation of lung cancer," The Journal of the Japanese Associtation for Chest Surgery, vol. 21, no. 7, pp. 942-945, 2007.

[12] T. Matsuoka, K. Sugi, E. Matsuda, K. Okabe, K. Hirazawa, and T. Azuma, "Mycobacterium avium complex (MAC) infection needed differential diagnosis of the recurrence after surgery for double lung cancer; report of a case," Kyobu Geka, vol. 60, no. 13, pp. 1200-1203, 2007.

[13] H. Ohtsuka, M. Kanzaki, T. Kikkawa, T. Obara, and M. Ishizawa, "A case of pulmonary granuloma occurring along the staple," Nihon Kyobu Rinsho, vol. 67, no. 11, pp. 977-980, 2008.

[14] H. Matsuoka, T. Miyoshi, M. Morimoto, N. Hino, and M. Tsuyuguchi, "Small size lung adenocarcinoma with local recurrence and port site recurrence 56 months after partial resection," Kyobu Geka, vol. 64, no. 13, pp. 1154-1157, 2011.

[15] H. Tempaku, M. Takao, H. Suzuki, A. Shimamoto, and H. Simpo, "Pulmonary foreign body granuloma on the staple line five years after wedge resection for metastatic lung cancer," The Journal of the Japanese Association for Chest Surgery, vol. 26, no. 1, pp. 52-55, 2012.

[16] N. Motono, A. Okada, and K. Togashi, "A foreign body granuloma on the staple-line after pulmonary resection for metastatic renal cell carcinoma," Japanese Journal of Lung Cancer, vol. 52, no. 1, pp. 23-26, 2012.
[17] K. Nakamura, H. Saji, R. Nakajima et al., "A Phase III randomized trial of lobectomy versus limited resection for small-sized peripheral non-small cell lung cancer (JCOG0802/ WJOG4607L)," Japanese Journal of Clinical Oncology, vol. 40, no. 3, pp. 271-274, 2009.

[18] R. Morinaga, I. Okamoto, K. Furuta et al., "Sequential occurrence of non-small cell and small cell lung cancer with the same EGFR mutation," Lung Cancer, vol. 58, no. 3, pp. 411-413, 2007.

[19] L. V. Sequist, B. A. Waltman, D. Dias-Santagata et al., "Genotypic and histological evolution of lung cancers acquiring resistance to EGFR inhibitors," Science Translational Medicine, vol. 3, no. 75, Article ID 75ra26, 2011. 


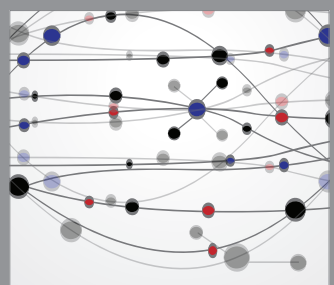

The Scientific World Journal
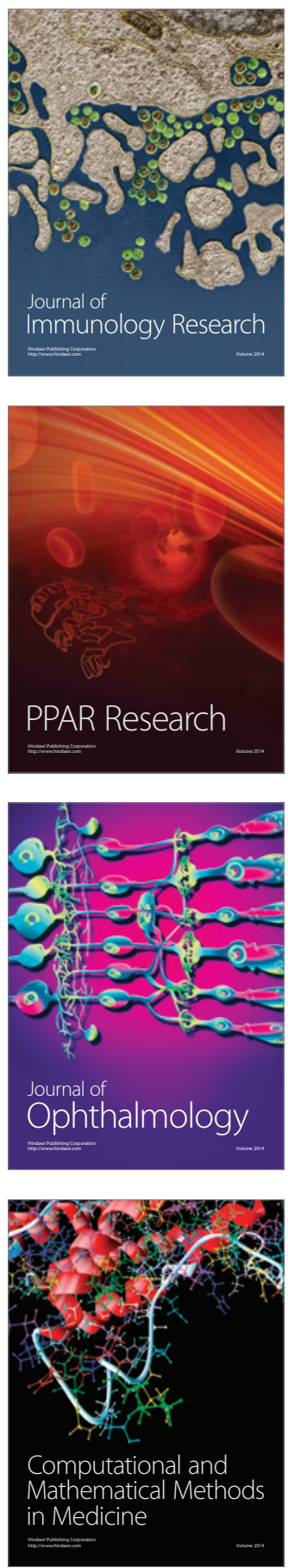

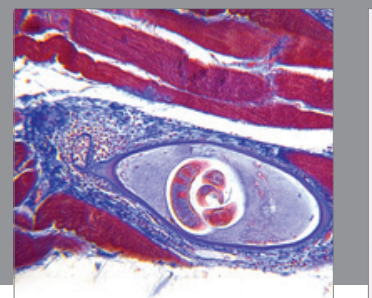

Gastroenterology

Research and Practice
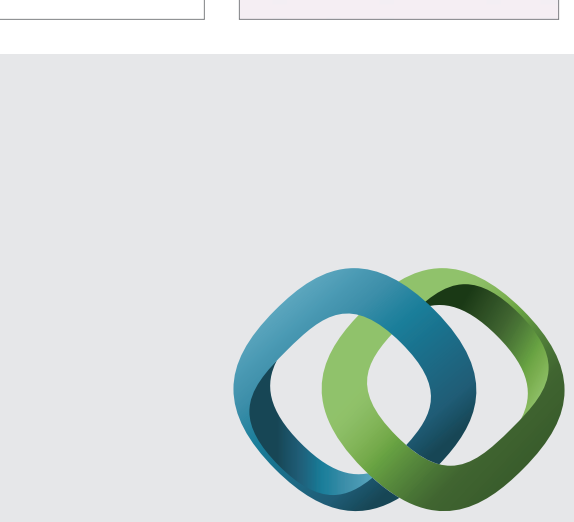

\section{Hindawi}

Submit your manuscripts at

http://www.hindawi.com
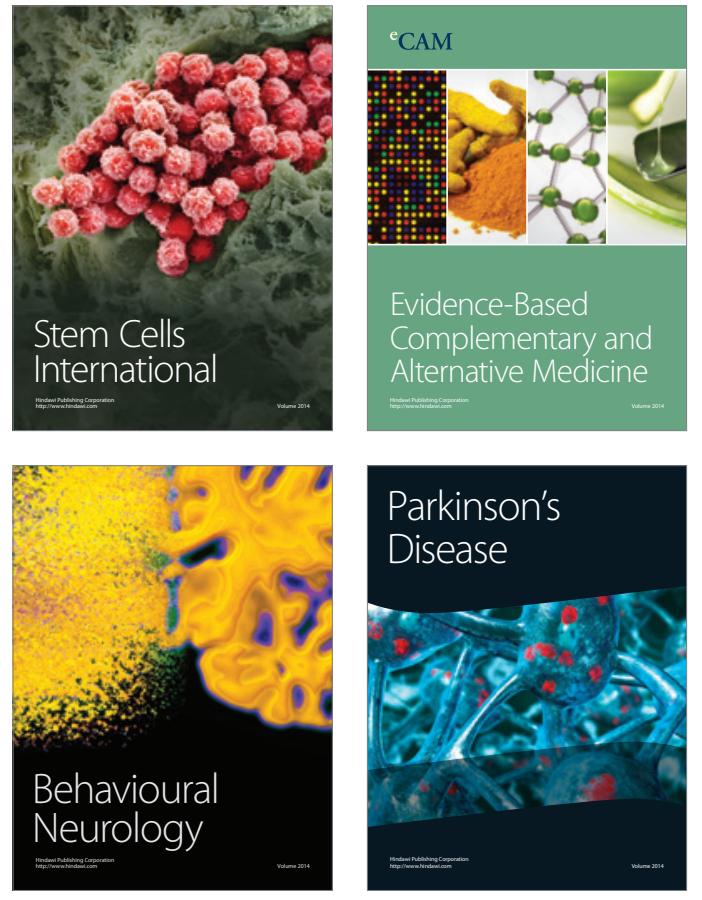
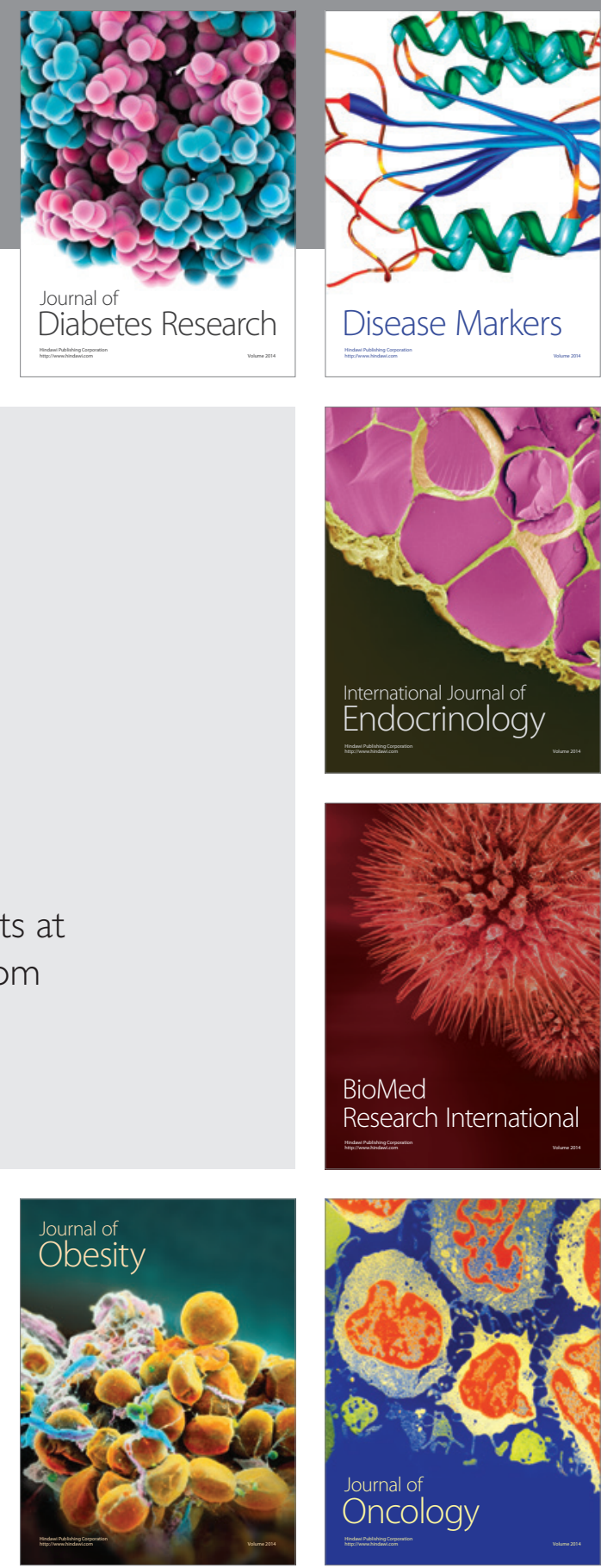

Disease Markers
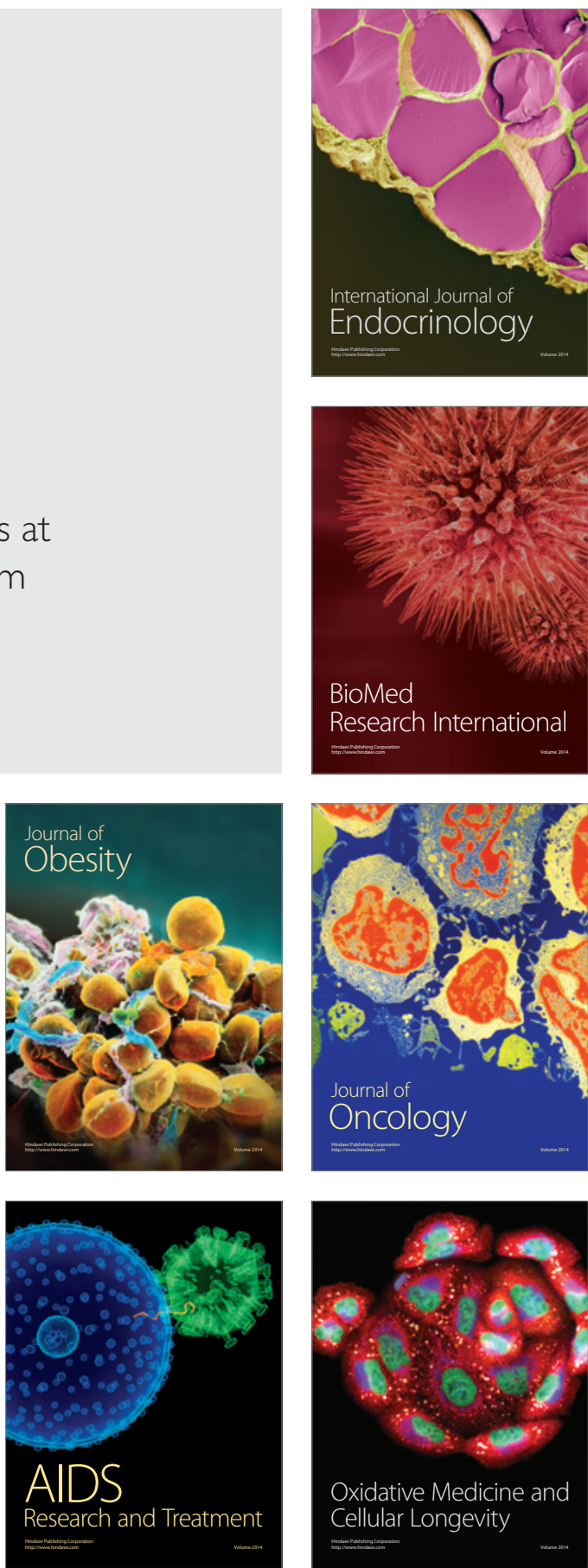